\title{
Impact of lactoferrin on bone regenerative processes and its possible implementation in oral surgery - a systematic review of novel studies with metanalysis and metaregression
}

Grzegorz Trybek1, Maciej Jedliński ${ }^{2,3},{\text { Aleksandra Jaroń }{ }^{1 *} \text { (D), Olga Preuss }{ }^{1}, \text { Marta Mazur }^{2} \text { and Anna Grzywacz }}^{4}$

\begin{abstract}
Background: Lactoferrin is an iron - binding glycoprotein with anti-inflammatory and anabolic properties found in many internal fluids. It is worth looking at novel studies, because of their methodology and observations that may once be applicable in modern implantology.

The aim of the study is to answer the question if lactoferrin is a promising factor for bone regenerative process in oral surgery.

Method: An electronic search was conducted on 14th October 2019 on the PubMed, Scopus and Web of Science databases. The keywords used in the search strategy were: lactoferrin AND bone regeneration AND oral surgery. The qualitative evaluation was conducted using the Jadad and Newcastle-Ottawa Quality Assessment Form. Then a metanalysis of a new bone growth and percentage of the resorbed graft were performed with the metaregression of lactoferrin dose to its outcome effects on bone regeneration.

Results: The search strategy identified potential articles: 133 from PubMed, 2 from Scopus, 4 from Web of science. After removal of duplicates, 136 articles were analyzed. Subsequently, 131 papers were excluded because they did not meet the inclusion criteria. The remaining 5 papers were included in the qualitative synthesis. The use of lactoferrin clearly increases the growth of a newly formed bone (2.58, Cl:[0.79, 4.37]), as well as shortens the time of the graft resorption $(-1.70, \mathrm{Cl}:[3.43,0.03])$ and replaces it with a species-specific bone. Heterogeneity is significant at $p<0.001$ level. Metaregression indicates that one unit increase in the log (Treatment dose), i.e. a 2.78 times increase of the Treatment dose, results in an increase of the Effect size by 0.682 .

(Continued on next page)
\end{abstract}

\footnotetext{
* Correspondence: jaronola@gmail.com

${ }^{1}$ Department of Oral Surgery, Pomeranian Medical University in Szczecin, al. Powstańców Wielkopolskich 72/18, 70-111 Szczecin, Poland

Full list of author information is available at the end of the article
}

(c) The Author(s). 2020 Open Access This article is licensed under a Creative Commons Attribution 4.0 International License, which permits use, sharing, adaptation, distribution and reproduction in any medium or format, as long as you give appropriate credit to the original author(s) and the source, provide a link to the Creative Commons licence, and indicate if changes were made. The images or other third party material in this article are included in the article's Creative Commons licence, unless indicated otherwise in a credit line to the material. If material is not included in the article's Creative Commons licence and your intended use is not permitted by statutory regulation or exceeds the permitted use, you will need to obtain permission directly from the copyright holder. To view a copy of this licence, visit http://creativecommons.org/licenses/by/4.0/ The Creative Commons Public Domain Dedication waiver (http://creativecommons.org/publicdomain/zero/1.0/) applies to the data made available in this article, unless otherwise stated in a credit line to the data. 
(Continued from previous page)

Conclusions: The use of lactoferrin both systemically and locally promotes anabolic processes (new bone formation). There is a relationship between the increase in administered dose of lactoferrin and the intensity of new bone formation. However, it is not only necessary to continue experimental research, but also to extend it to the clinical studies on patients, due to the limitations of different animal model research and different methodology, to introduce lactoferrin as a standard procedure for the treatment of bone defects, because it is a promising product.

Keywords: Lactoferrin, Bone regeneration, Bone remodeling, Dental implants, Animal study, Oral surgery

\section{Background}

Lactoferrin is glycoprotein $80 \mathrm{kDa}$ able to chelate two ferric ions per molecule. It is a component of many externally secreted substances such as saliva, tears, colostrum, milk, gastrointestinal fluids, nasal and bronchial mucosa [1]. Lactoferrin contains 691 amino acid residues assembled into two homologous lobes connected through a peptide. All these structures form a 3-turn $\alpha$ helix. This glycoprotein is able to retain iron ions in the chelated form to $\mathrm{pH}$ values as low as 3.0. Because of its structure, it is a component of the innate immune response and a potent immunomodulator [2, 3]. Its ability to bind free iron ions as well as deactivate reactive oxygen forms prevents the tissues from excessive inflammatory processes and also decreases bacterial growth and the development of biofilm [2, 4].

It was also found to have a direct effect on cell differentiation and growth [5], as well as modulation of the cytokine production processes i.e. the ones with direct impact on bone tissue regeneration and growth [6-8]. Lactoferrin stimulates the growth and activity of chondrocytes and osteoblasts, while inhibiting osteoclastogenesis, without affecting mature osteoclast activity [9]. Its administration decreases secretion of a number of cytokines such as tumor necrosis factor $\alpha$ (TNF $\alpha)$ and interleukin 1 beta (IL-1 $\beta$ ) which promote osteolytic processes in tissues [7, 8], and at the same time stabilize the balance in the Receptor activator of nuclear factor $\mathrm{K} \mathrm{B}$ (RANK)/ Receptor activator of nuclear factor $\mathrm{\kappa} B$ Ligand (RANKL)/ osteoprotegrin (OPG) system [9]. Since the discovery of the RANKL / RANK / OPG system in the mid-1990s, there is a much more considerable understanding of osteoclast formation and activation. Osteoblasts and stromal stem cells express the receptor activator of ligand (RANKL), which binds to its receptor, RANK, on the surface of osteoclasts and their precursors which activate them. If the ligand is present, this system increases the differentiation of precursors into multinucleated osteoclasts and the activation of osteoclasts and survival in both physiological and pathological conditions associated with increased bone resorption. When the ligand is no ligand, the differentiation of osteoclast is decreased. Osteoprotegrin (OPG) is secreted by osteoblasts and osteogenic stromal stem cells and protects the skeleton from excessive bone resorption by binding to RANKL and preventing its interaction with RANK [10]. Lactoferrin stabilizes the osteinductive effect of hydroxyapatite crystals by acting on osteoblast and osteoclast cells through the RANK / RANK / OPG system mentioned above [11].

In 2006 it was discovered how lactoferrin acts by directly reinforcing bone healing processes at the cellular level [12]. Lactoferrin has a mitogenic effect on osteoblasts close to the wound, mediating through the lowdensity lipoprotein receptor-related protein-1 (LRP1) and activating two kinases of osteoblast cells: p42/44 mitogen-activated protein kinase (MAPK) and the PI3kinase-dependentphosphorylation of Akt [12]. Recently, lactoferrin has become the focus of many studies. This increasing interest may result from a deeper understanding of its function and from its greater availability to scientists and practitioners. This results from the fact that the species of origin and the method of preparation of lactoferrin does not substantially affect the extent of proliferation on osteoblast cells [8], which makes the studies on lactoferrin and its possible implementation in medicine cheaper and more universal.

\section{Aim of the study}

The aim of the study is to answer the question if lactoferrin is a promising factor for bone regenerative process in oral surgery.

\section{Method}

\section{Search strategy}

This review was performed under the PRISMA guidelines [13]. The results are presented in and Fig. 1. An electronic search was conducted on 14th October 2019 on the PubMed, Scopus and Web of Science databases. All searches were conducted using a combination of subject headings and free-text terms: we determined the final search strategy through several pre-searches. The keywords used int the search strategy were: lactoferrin AND bone regeneration AND oral surgery. Reference lists of primary research reports were cross-checked in an attempt to identify additional studies. 


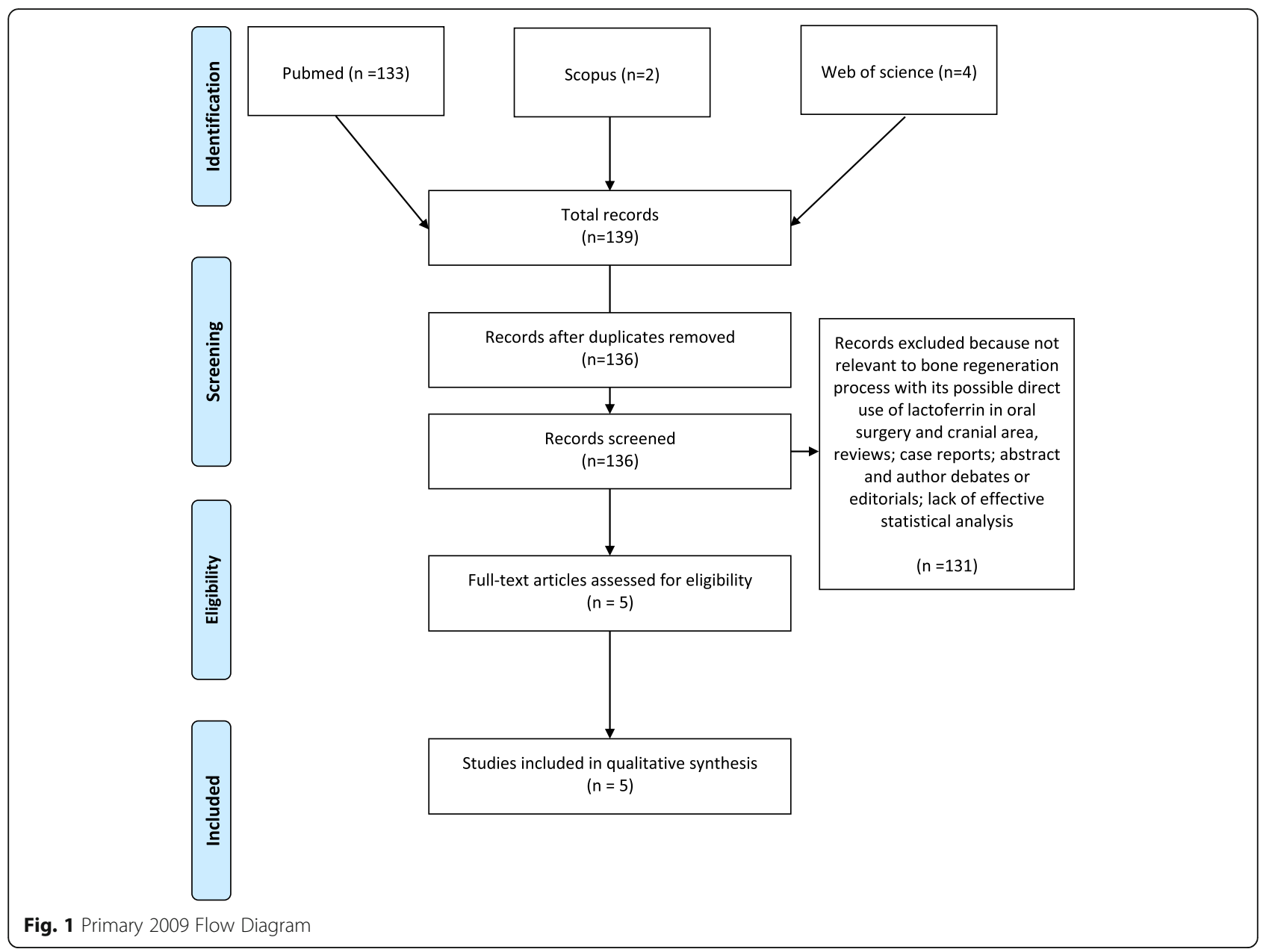

\section{Eligibility criteria}

The following inclusion criteria were employed for this systematic review: (1) randomized clinical trial; (2) cohort study; (3) case-control study; (4) articles published in the last 10 years; (5) studies carried out on human subjects; animal subjects (6) results published in English (7) studies on lactoferrin impact on bone tissues.

The following were the exclusion criteria: (1) reviews; (2) case reports (3) abstract and author debates or editorials; (4) studies not related to bone regeneration; (5) papers not related to possible direct use of lactoferrin in oral surgery; (6) lack of effective statistical analysis.

\section{Data extraction}

First, two reviewers selected the studies by reading titles and abstracts and then by studying the full texts of select articles (MJ and OP). Any doubt or disagreement between the two reviewers was resolved by discussion with a third author (AJ). All data extracted from the selected studies are shown in the Table 1.

\section{Quality assessment}

The quality assessment was performed using the Jadad scale for reporting randomized controlled trials for RCT and RCCT studies [19]. The results are shown in Table 2. In assessment it was taken into account if the study was randomized and double-blinded with appropriately described methods. For every characteristic evaluated a point was given. Assessment ranged from zero to five with a high score indicating a good quality of study. Notwithstanding, for Case-control Studies the Newcastle-Ottawa Quality Assessment Form [20] was used. The results are shown in Table 3. The qualities of all included case-control studies were based on object selection, comparability, and exposure. The possible quality assessment score ranged from zero to nine points with a high score indicating a good quality study. For each characteristic evaluated one point was given. To investigate the risk of a publication bias, our search was conducted on www.controlled-trials.com and www.clinicaltrials.gov to verify the number of ongoing studies in this field. No such studies were found. 


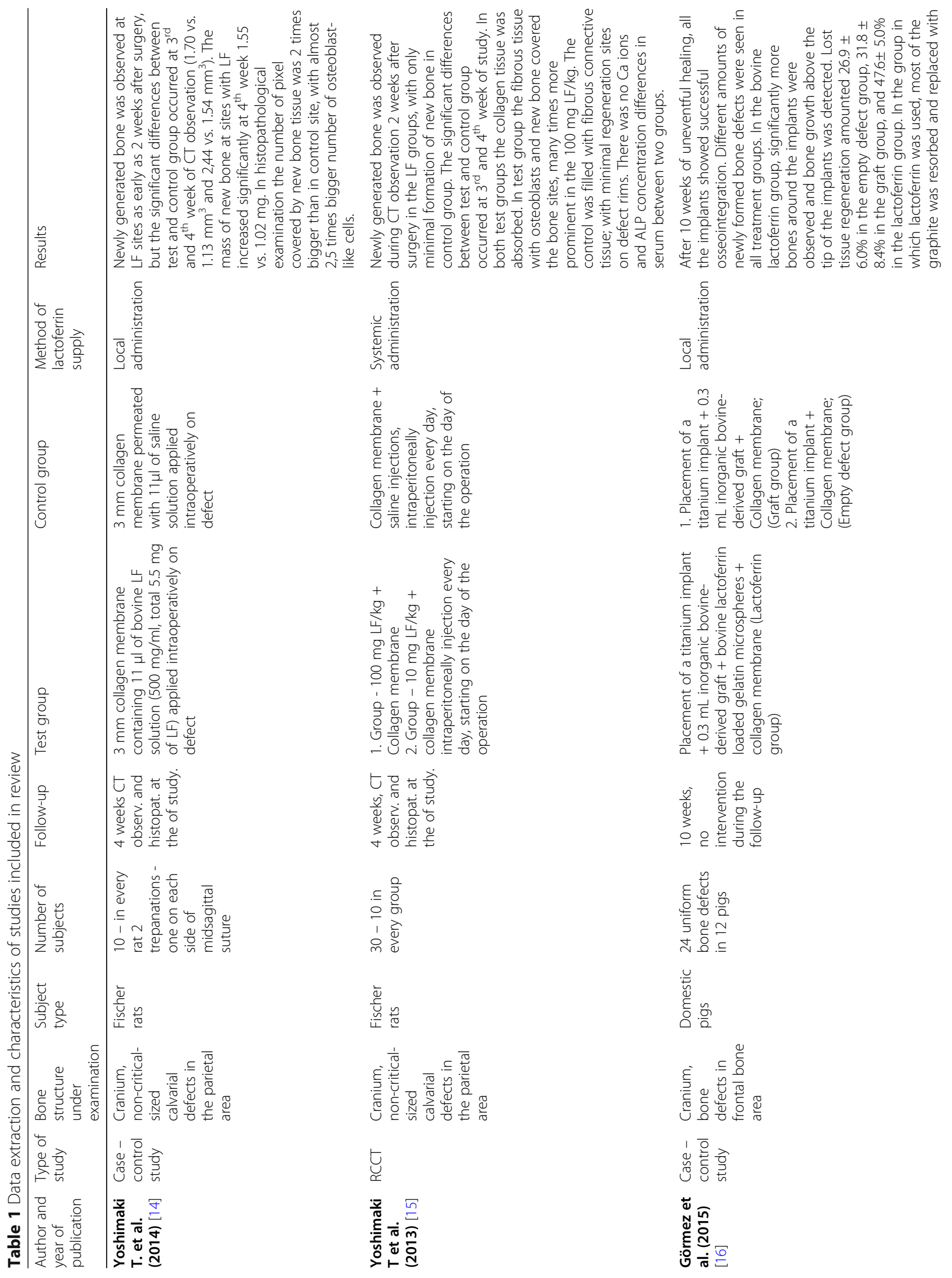




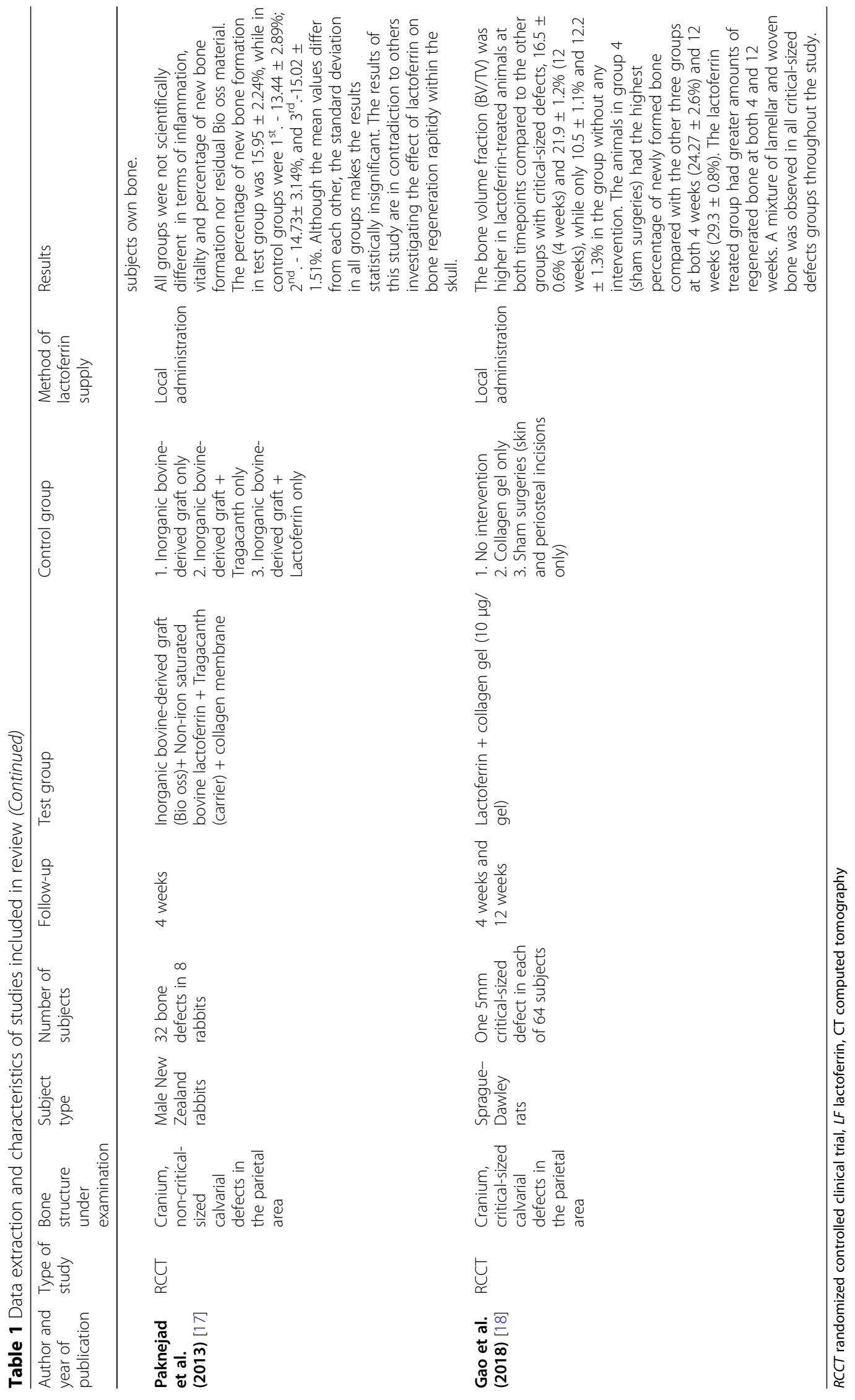


Table 2 Scoring according to Jadad scale for reporting randomized controlled trials [19]

\begin{tabular}{llll}
\hline Author & Yoshimaki T. et al. (2014) [14] & Paknejad et al. (2013) [17] & Gao et al. (2018) [18] \\
\hline Randomization present & 1 & 1 & 1 \\
Appropriate randomization used & 1 & 1 & 1 \\
Blinding present & 0 & 1 & 1 \\
Appropriate blinding used & 0 & 0 -not described & $0-$ not described \\
Appropriate long-term follow-up for all patients & 1 & 1 & 1 \\
Total & 3 & 4 & 4 \\
\hline
\end{tabular}

\section{Summary measures and heterogeneity}

A percentage of bone regeneration and differences in the residual amount of the graft were taken as a measure of treatment efficacy for both groups - Treatment group (TG) and Control group (CG). Meta-analysis was performed using the random-effect model via metafor and compute.es R packages, with Standardized Mean Differences (SMD) and 95\% confidence intervals (95\% CI) being calculated as effect estimates. Heterogeneity was assessed quantitatively using I2-statistics and Cochran's $Q$ [21]. In studies examining more than one factor affecting bone regeneration, the test and control groups were separated so that the only differentiating factor was the use of lactoferrin, or lack of it. There were 5 literature positions included in metaanalysis. Treatments with 10 and $100 \mathrm{mg} / \mathrm{kg}$ in Yoshimaki et al. [15] were treated as separate studies, as well as the cases with and without a carrier in Paknejad et al. [17] and 4 and 12 weeks measurements in Gao et al. [18] These resulted in 8 studies for bone regeneration and 3 studies for Differences in the residual graft percentage.

\section{Metaregression of a lactoferrin dose to its outcome effects on bone regeneration}

To perform metaregression, only papers enabling full conversion of lactoferrin doses between studies were used (mg/kg.b.w). In order to determine if the treatment dose accounts for the dispersion in the summary effect, meta-regression model

$$
\text { Effect size }=\beta_{0}+\beta_{1} \log (\text { treatment dose })
$$

was examined. The input data are presented in Table 4.

\section{Results}

\section{Search results}

The search strategy identified potential articles: 133 from PubMed, 2 from Scopus, 4 from Web of science. After

Table 3 Scoring according to Newcastle-Ottawa Quality Assessment Form for Case-control Studies [20]

\begin{tabular}{|c|c|c|c|}
\hline Study & Terms & Görmez et al. (2015) [16] & Yoshimaki T. et al. (2013) [14] \\
\hline \multirow[t]{4}{*}{ Selection } & $\begin{array}{l}\text { Is the case definition } \\
\text { adequate? }\end{array}$ & 1 & 1 \\
\hline & $\begin{array}{l}\text { Representativeness of the } \\
\text { cases }\end{array}$ & 1 & 1 \\
\hline & Selection of Controls & 1 & 1 \\
\hline & Definition of Controls & 1 & 1 \\
\hline \multirow[t]{2}{*}{ Comparability } & \multirow{2}{*}{$\begin{array}{l}\text { Comparability of cases } \\
\text { and controls on the basis } \\
\text { of the design or analysis }\end{array}$} & 2 & 2 \\
\hline & & $\begin{array}{l}\text { Both test and control surgical sites underwent the } \\
\text { same procedure at the begging of the study. The } \\
\text { race, age and the breeding place in every group } \\
\text { were the same. Confidence in comparability of } \\
\text { results is contributed by the fact that both test and } \\
\text { control sites were in the same individuals. }\end{array}$ & $\begin{array}{l}\text { Both test and control groups underwent the same } \\
\text { procedure at the begging of the study. The race, } \\
\text { age and the breeding place in both groups were } \\
\text { the same. Authors maintain, that all the subjects } \\
\text { got the same number of injections at a similar } \\
\text { frequency. }\end{array}$ \\
\hline \multirow[t]{3}{*}{ Outcome } & $\begin{array}{l}\text { Ascertainment of } \\
\text { exposure }\end{array}$ & 1 & 0 - not described \\
\hline & $\begin{array}{l}\text { Same method of } \\
\text { ascertainment for cases } \\
\text { and controls }\end{array}$ & 1 & 0 - not described \\
\hline & Non-Response rate & No description & No description \\
\hline Total & & 8 & 6 \\
\hline
\end{tabular}


Table 4 Characteristics of Metaregression with the method of calculating the dose throughout the studies

\begin{tabular}{lll}
\hline & Effect size & Treatment dose (mg/kg.b.w) \\
\hline Yoshimaki T. et al. (2014) [14] & 1.19 & 20 \\
Yoshimaki T et al. (2013) [15] 100mg/kg & 2.02 & 100 \\
Yoshimaki T et al. (2013) [15] 10mg/kg & 0.62 & 10 \\
Paknejad et al. (2013) [17] w/o carrier & 0.40 & 10.77 \\
Paknejad et al. (2013) [17] with carrier & 0.46 & 10.77 \\
\hline
\end{tabular}

removal of duplicates, 136 articles were analyzed. Subsequently, 131 papers were excluded, because they did not meet the inclusion criteria. The remaining 5 papers were included in the qualitative synthesis (Flow diagram). Three of them are RCTs, while 2 of them are casecontrol studies. Table 1 summarizes the characteristics for each of the 5 studies included.

\section{Quality assessment and the risk of bias}

None of the RCTs has received a maximum score on the Jadad Scale. This is due to the fact, that Yoshimaki et al. [20] did not use any type of blinding. Although Paknejad et al. [17] and Gao et al. [18] reported that the histological analysis was conducted by a blinded pathologist, there is no description of the blinding method in the article, hence a lack of certainty about its appropriateness. Because of the randomness of the way bone defects were filled during surgery in the same animal $[15,17]$ and full randomization of the selection of subjects in the Gao et al. study [18], without any doubts the randomization and the methods of its use were proper in all RCT studies. Case-control studies $[14,16]$ are characterized by their good methodological value. Both authors precisely described the test and control groups. Görmez et al. [16] assured the comparability of cases and controls by making similar bone defects in small group of animals of the same race from the same breed. The specimens were examined with the same equipment. On the other hand, in the Yoshimaki et al. [15] study, due to the method of lactoferrin supply (postoperative injections), a specific method of ascertainment of exposure was needed, which, unfortunately, was not described. Also, in this study all the specimens were examined with the same equipment [14]. Despite all of this, it should be pointed out that the limitations of the studies were included in this review. First of all, in all RCTs, even if it was reported that blinding was used, none of them described it thoroughly enough to determine if it was appropriate. It was practically in every study that a new bone tissue formation was observed. No consistent timepoint in the follow-up between them was found, which prevents us from a direct comparison of the test results and forces to compare them only by EF (effect size), which increases the risk of bias. Only - Görmez et al. [16] and Gao et al. [18] reported in their studies, that the temperature during drilling a defect was $37^{\circ} \mathrm{C}$ and it was stable during the procedure, which is crucial for osteoblast survival in the immediate vicinity of the defect and therefore for a possible anabolic effect of lactoferrin on bone tissue. In 1983, Eriksson and Albrektsson proved irreversible histological changes in a rabbit's tibia as a result of applying the temperature of $47^{\circ} \mathrm{C}$ for more than $1 \mathrm{~min}$. Even more damage occurred when the temperature rose to $53^{\circ} \mathrm{C}$. Overheating the bone tissue for more than $1 \mathrm{~min}$ at $60^{\circ} \mathrm{C}$ causes complete interruption of the blood supply and tissue necrosis without the appearance of reconstruction exponents for up to 100 days of observation [22].

\section{Metanalysis}

The results are shown in Fig. 2. Positive values of SMD indicates greater efficacy in TG (lactoferrin usage), negative - greater efficacy in CG.

Lactoferrin usage appears to have a large positive effect size $(2.58$, CI:[0.79, 4.37]) on bone regeneration, and it is large accordingly to Cohen's interpretive guidelines [23] on bone regeneration in relation to the control group. Heterogeneity is significant at $p<0.001$ level. The results of available studies are very different. $95.1 \%$ of the variability comes from heterogeneity (variability in sizes of effects that result from true differences among the studies) [24]. Large part of heterogeneity is introduced by Görmez et al. [16] and Gao [18] in their studies. In the Görmez and Gao studies the healing process lasted longer than in most of the studies mentioned above. Additionally, in Gao study lactoferrin was applied in different gel form (supplementary to collagen gel) than in the rest of the studies.

In each test group, faster graph resorption is noticeable $(-1.70, \mathrm{Cl}:[3.43,0.03])$. The results are shown in Figs. 3 and 4.

It should be noted that a larger amount of the resorbed graft is always associated with a simultaneously greater increase in a newly formed bone, as a result of which the bovine bone is replaced by the species-specific tissue (newly formed bone), while maintaining the 


\section{Increase in formation of new bone due to lactoferrin in all included studies}

\begin{tabular}{|c|c|c|c|}
\hline Study & $\mathrm{TG} / \mathrm{CG}$ & & SMD $[95 \% \mathrm{Cl}]$ \\
\hline Yoshimaki (2014) & $10 / 10$ & : & $1.19[0.24,2.15]$ \\
\hline Yoshimaki (2013), 100mg/kg & $10 / 10$ & $\mapsto-1$ & $2.02[0.94,3.10]$ \\
\hline Yoshimaki (2013), 10mg/kg & $10 / 10$ & $H$ & $0.62[-0.28,1.51]$ \\
\hline Görmez (2015) & $8 / 8$ & $\longmapsto$ & $3.28[1.78,4.78]$ \\
\hline Paknejad (2013) w/o carrier & $8 / 8$ & -1 & $0.40[-0.59,1.39]$ \\
\hline Paknejad (2013) with carrier & $8 / 8$ & -1 & $0.46[-0.53,1.45]$ \\
\hline Gao (2018), 4 weeks & $20 / 20$ & $\longmapsto$ & $-7.19[5.50,8.88]$ \\
\hline Gao (2018), 12 weeks & $20 / 20$ & $\longmapsto$ & $5.99[4.54,7.44]$ \\
\hline \multirow{3}{*}{$\begin{array}{l}\text { Total } \\
I^{2}=95.1 \%, Q=97.68, p<0.001\end{array}$} & & - & $2.58[0.79,4.37]$ \\
\hline & $\Gamma$ & \begin{tabular}{l|l|l|l|l|l}
1 & 1 & 1 & 1
\end{tabular} & $\neg$ \\
\hline & -2 & $\begin{array}{lllll}0 & 2 & 4 & 6 & 8\end{array}$ & 10 \\
\hline
\end{tabular}

Fig. 2 Metanalysis Tree Diagram - This diagram shows the acceleration of the healing effect relative to the control sample among all the study groups in the articles included in the review

overall volume of bone tissue, which indicates stimulation of the regeneration process and undoubtedly should be considered as a successful treatment.

\section{Metaregression of a lactoferrin dose to its outcome effects on bone regeneration}

Slope parameter $\beta 1$ is statistically significant. One unit increase in the $\log$ (Treatment dose), i.e. a 2.78 times increase of the Treatment dose, results in an increase of the Effect size by 0.682 . The treatment dose moderator accounts for a large proportion of the between-study variance, reducing $\mathrm{I}^{\wedge} 2$ estimate to zero, but has a high upper bound of confidence interval, so this result should be interpreted cautiously. However, they indicate a positive effect of increasing the dose on the percentage gain of a newly formed bone. The results of the model valuation are presented in Tables 4 and 5 and Figs. 5 and 6.

\section{Summarizing findings}

Our findings show inconsistent results on both measurements - bone regeneration and differences in residual. The bone regeneration treatment dose appears to be a good moderator for this inconsistency, at least when lactoferrin is applied locally. Unfortunately, there are too few studies to check if it is also the case for differences in the residual graft.

For all the studies the publication bias was assessed by analyzing funnel plots for differences in the residual graft as well as for bone regeneration. No significant bias of publications in the field of bone regeneration was detected in studies on smaller mammals (mice, rats, rabbits). Most of the degree of heterogeneity is caused by Görmez's and Gao's results.

\section{Discussion}

As a stabilizer for the immune response to the inflammatory process lactoferrin has undoubtedly a visible 


\section{Differences in residual graft percentage when using lactoferrin}

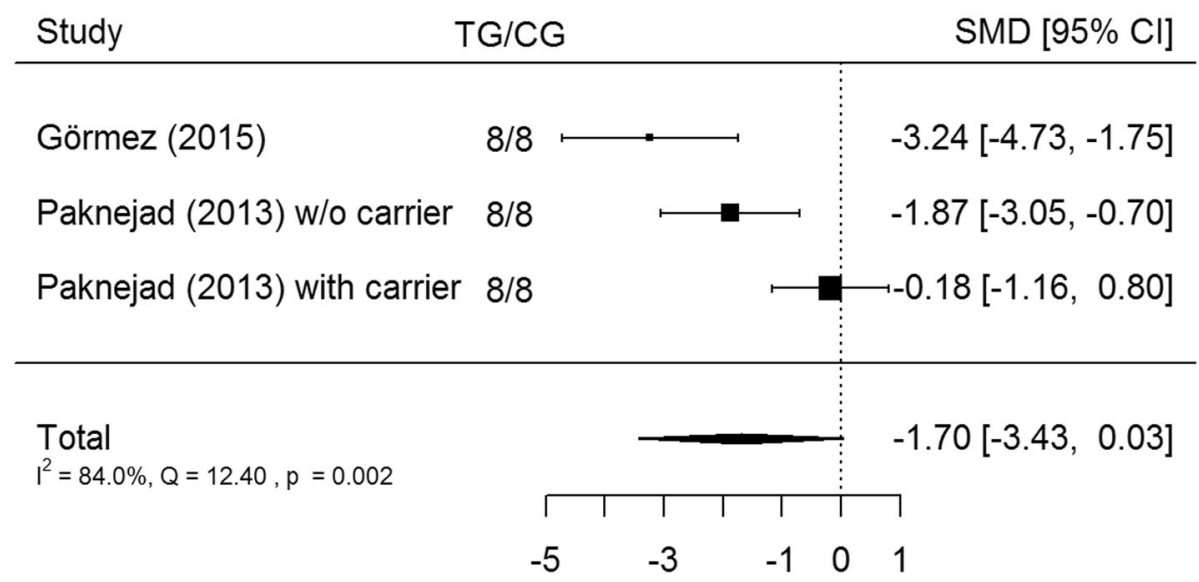

\section{Standardized Mean Difference}

Fig. 3 Metanalysis tree diagram - This diagram shows the acceleration of graft resorption relative to the control sample among all study groups in the articles included in the review. Along with the resorption of graft, it was replaced with host tissue

effect on the process of bone formation. Many studies carried out in other parts of the body of experimental animals clearly indicate its positive effect $[25,26]$. Recently it has been proved that the process of osteodistraction within rabbit's fibula occurs more efficiently and has more stable results. Authors suggested that the increased tissue growth relative to the control group is attributed to the tilting balance in the RANK / RANKL /
OPG system towards increased osteoprotegrin expression and significant decrease expression of RANK-ligand [11]. The same effect is indicated by the study carried out by Montesi et al. on cells culture [10].

In an organ culture study of intraverbal discs it was found that the addition of lactoferrin causes a number of not only anabolic but also anti-catabolic reactions. Through inhibiting the reaction sequence caused by Il-1

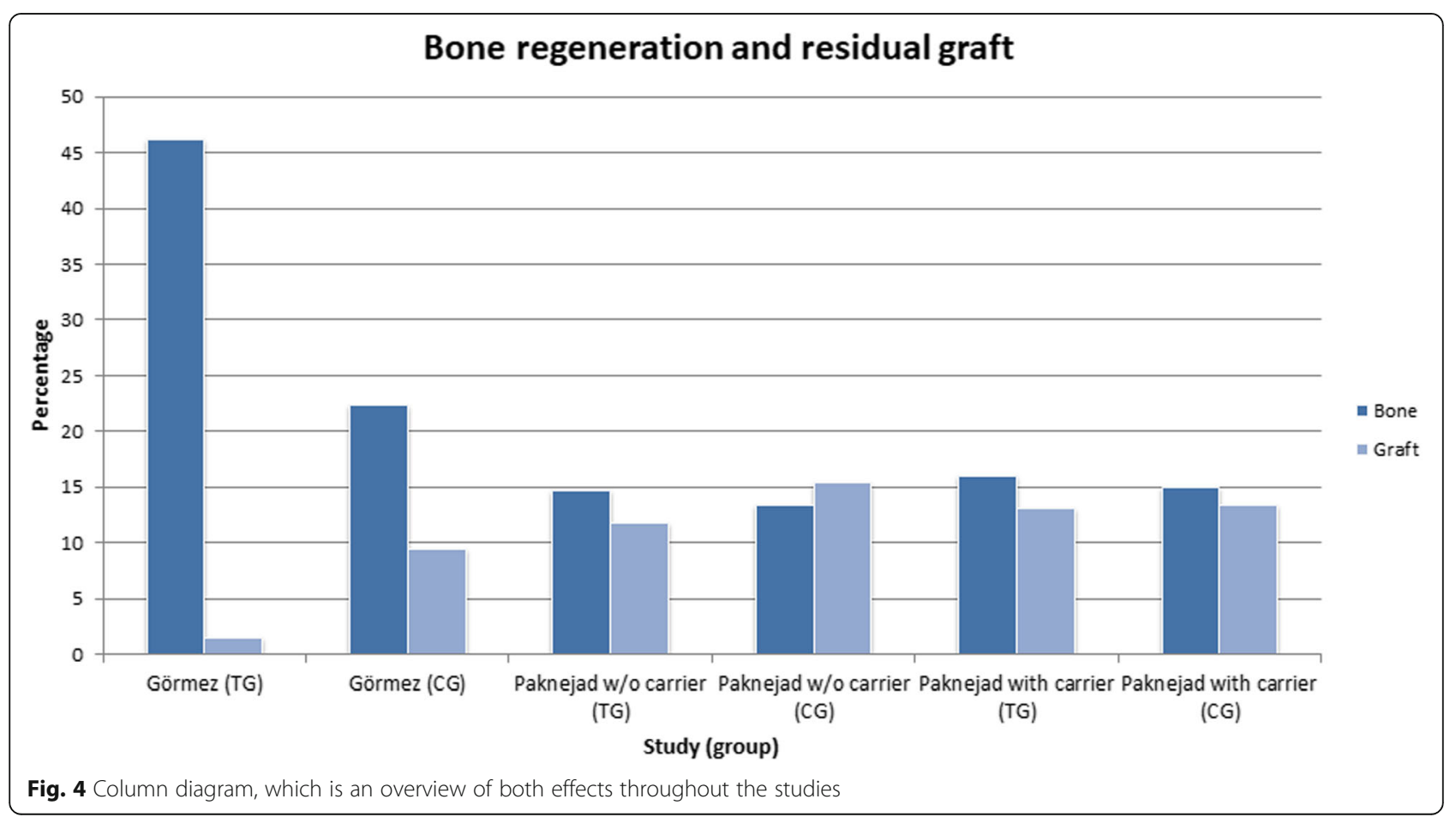


Table 5 Characteristics of Metaregression

\begin{tabular}{llll}
\hline Parameter & Estimate \pm SD & $z$ & $p$ \\
\hline$\beta_{0}$ & $-1.047 \pm 0.810$ & -1.293 & 0.196 \\
$\beta_{1}$ & $0.681 \pm 0.273$ & 2.498 & 0.012 \\
Heterogeneity & & & \\
$P^{2}$ & ${ }^{2} \mathrm{Cl}$ & $\mathrm{Q}$ & $\mathrm{p}$ \\
$0.00 \%$ & {$[0.00,44.64 \%]$} & 0.338 & 0.943 \\
\hline
\end{tabular}

and lipopolisacharid (LPS) lactoferrin reduced the expression of multiple metaproteinaseas and disintegrin and metalloproteinase with thrombospondin motifs (ADAMTS) at the mRNA level, thus reducing tissue degeneration in bovine, rabbit and mouse cells in vivo and ex vivo [25]. Additionally, it increases several times the bone morphogenic protein 7 (BMP-7) gene expression relative to the control group. Furthermore, lactoferrin diminishes the presence of nitric oxide, which was associated as a pro-inflammatory factor, which leads to cartilage destruction in knee joints and spine discs $[10,11,25]$. Pelletier JP et al. indicted that the higher level of nitric oxide is directly proportional to a higher level of metalloproteinases (MMPs) [24]. The results of such studies are promising, because the human is one of the most biologically responsive species to bovine lactoferrin [27]. Several authors who also examined the degree of graphite resorption during a longterm follow-up found that the bovine graft (BioOss), used in all the studies, is gradually resorbed and replaced with the host bone with only a slight decrease in the bone volume [28]. Not only slow resorption [29], but also no resorption within six years [30] were reported in the literature. Among the studies reviewed in the review - Görmez et al. [16] found that the addition of lactoferrin during implantation significantly accelerates this process, even with a short (4 weeks) follow-up (-3.42!). In research conducted by Paknejad et al. [17] the differences are also noticeable, but they are not so staggering. However, there is always the effect of speeding up the graft replacement process. With one exception (Yoshimaki et al.) [15], lactoferrin was administered locally in all evaluated studies. The question should be asked: Where does this tendency come from? During the implantation procedure, topical agents are already used to increase osteoblast proliferation, such as various growth factors, platelet-derived growth factor (PDGF) [31], and accelerate their differentiation such as bone morphogenetic protein-2 [32]. Through its interaction with preosteoblasts lactoferrin provides an acceleration of both processes. Additionally, locally active lactoferrin increases the amount of growth factors, which can be combined with implants or orthopedic scaffolds to act synergistically in order to improve osseointegration and ultimately lead to better clinical results. What is more, systemic administrated lactoferrin is characterized by poor bioavailability in human subjects [33]. Free lactoferrin is a protein simply digested in the digestive system. The form of injection used by Yoshimaki et al. [14] overcame the problem of absorbability in the gastrointestinal tract, but it seems practically impossible to be introduced in a typical daily practice, whereas a local application as a possible alternative treatment is available. The possibility of using lactoferrin as a component of a dressing or collagen membranes during surgery saves the patient from an unpleasant series of injections and is much less time consuming. Nowadays, it should be stated that the therapeutic and utility potential of this glycoprotein should be considered untapped.

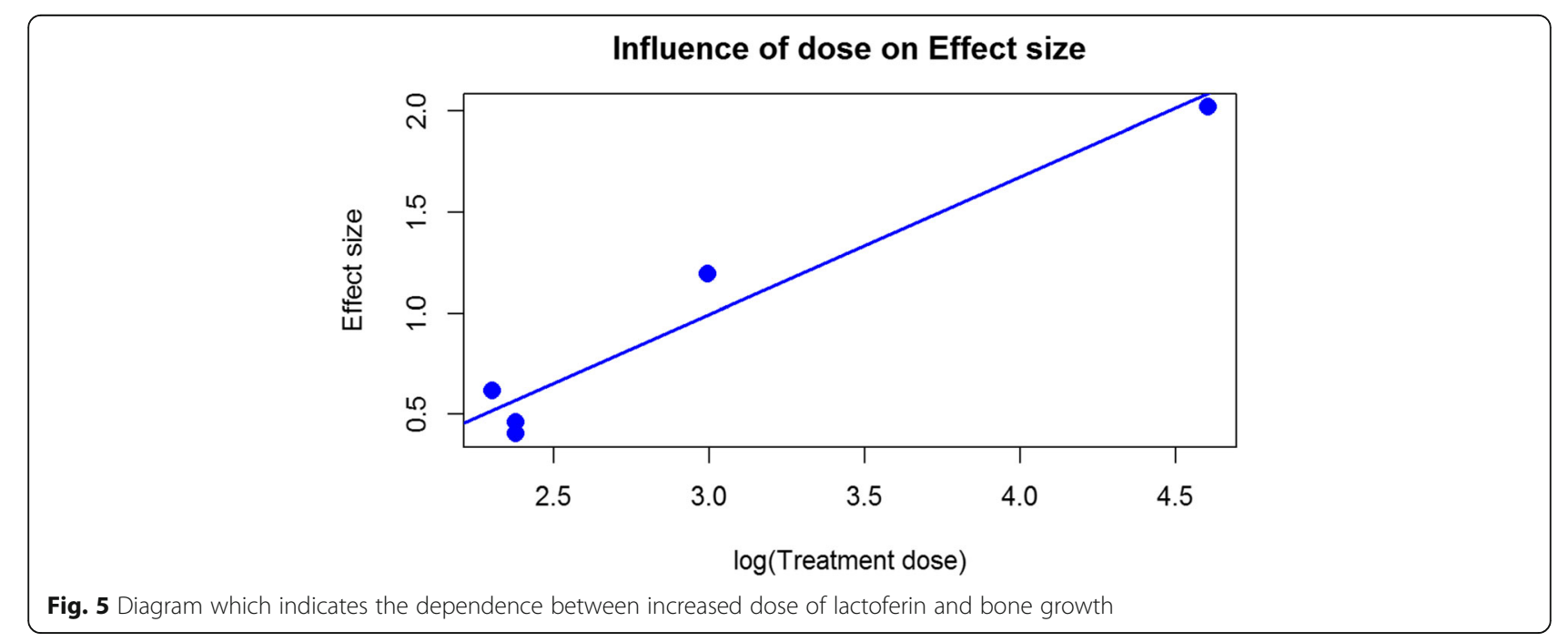




\section{Increase in the new bone formation - studies included in metaregression}

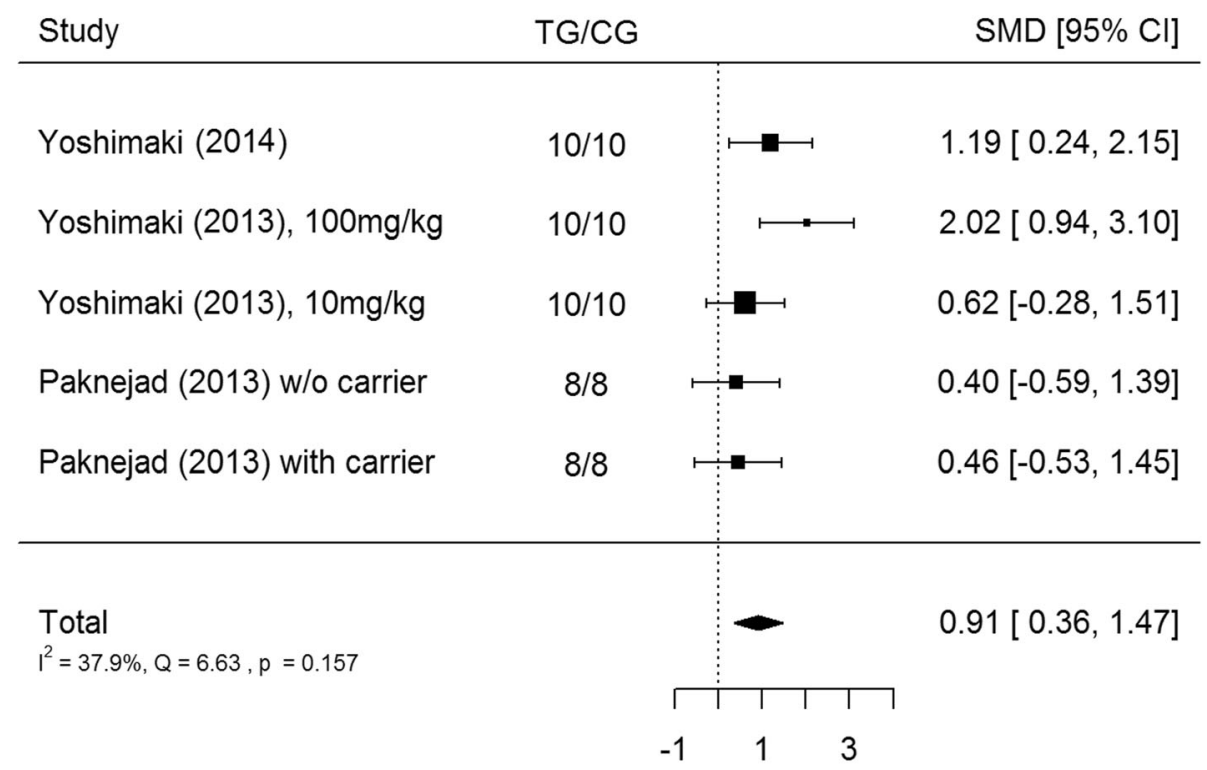

Standardized Mean Difference

Fig. 6 Metaregression tree diagram

\section{Conclusions}

Experiments using an animal model suggest that lactoferrin may be a useful factor in the regeneration of bone defect in the head and neck area. However, the purpose of our research was to determine whether it is a promising factor for bone regeneration in oral surgery. Nevertheless, it is not only necessary to continue experimental research, but also to extend it to the clinical studies on patients, due to the limitations of different animal model research and different methodology, to introduce lactoferrin as a standard procedure for the treatment of bone defects, because it is a promising product.

\section{Abbreviations}

TNFa: Tumor necrosis factor $a$; IL-1 $\beta$ : Interleukin 1 beta; RANK: Receptor Activator for Nuclear Factor k B; RANKL: Receptor Activator for Nuclear Factor K B Ligand; OPG: Osteoprotegrin; LRP: Low-density lipoprotein receptorrelated protein-1; MAPK: Mitogen-activated protein kinase; TG: Treatment group; CG: Control group; SMD: Standardized mean difernces; LPS: Lipopolischarid; ADAMTS: A disintegrin and metalloproteinase with thrombospondin motifs; BMP - 7: Bone morphogenic protein 7; MMPs: Metalloproteinases; PDGF: Platelet-derived growth factor

\section{Acknowledgements}

Not applicable.

\section{Authors' contributions}

All authors had read this paper and the final version submitted has been approved by all the authors. GT: research idea, study design. MJ: qualitative analysis, manuscript preparation, metanlysis and metareggresion. AJ: data extraction, manuscript preparation. OP: data extraction. MM: literature search. AG: manuscript preparation.
Funding

No external funding was reported by authors.

Availability of data and materials

Not applicable.

Ethics approval and consent to participate

Not applicable.

Consent for publication

Not applicable.

\section{Competing interests}

The authors declare that they have no competing interests.

\section{Author details}

${ }^{1}$ Department of Oral Surgery, Pomeranian Medical University in Szczecin, al. Powstańców Wielkopolskich 72/18, 70-111 Szczecin, Poland. ²Department of Oral and Maxillo Facial Sciences, Sapienza University of Rome, Via Caserta 6, 00161 Rome, Italy. ${ }^{3}$ Student Scientific Society at the Department of Oral Surgery, Pomeranian Medical University in Szczecin, al. Powstańców Wielkopolskich 72/18, 70-111 Szczecin, Poland. ${ }^{4}$ Independent Laboratory of Health Promotion, Pomeranian Medical University in Szczecin, ul. Gen.

Dezyderego Chłapowskiego 11, 70-103 Szczecin, Poland.

Received: 1 February 2020 Accepted: 9 August 2020

Published online: 26 August 2020

\section{References}

1. ligo M, Alexander DB, Long N, Xu J, Fukamachi K, Futakuchi M, Takase M, Tsuda $\mathrm{H}$. Anticarcinogenesis pathways activated by bovine lactoferrin in the murine small intestine. Biochimie. 2009:91:86-101.

2. Legrand D. Overview of Lactoferrin as a Natural Immune Modulator. J. Pediatr. 2016:173:10-5.

3. Baveye S, Elass E, Mazurier J, Spik G. Legrand D Lactoferrin: a multifunctional glycoprotein involved in the modulation of the inflammatory process. Clin Chem Lab Med. 37:281-6. 
4. Valenti P, Antonini G. Lactoferrin: an important host defence against microbial and viral attack. Cell Mol Life Sci. 2005;62:2576-87.

5. Bi BY, Lefebvre AM, Duś D, Spik G, Mazurier J. Effect of lactoferrin on proliferation and differentiation of the Jurkathuman lympoblastic T cell line. Arch Immunol Ther Exp (Warsz). 1997;45(4):315-20.

6. Cornish J. Lactoferrin promotes bone growth. Biometals. 2004;17(3):331-5.

7. Zimecki M, Miedzybrodzki R, Szymaniec S. Oral treatment of rats with bovine lactoferrin inhibits carrageenan-induced inflammation; correlation with decreased cytokine production. Arch Immunol Ther Exp (Warsz). 1998; 46:361-5.

8. Zimecki M, Wlaszczyk A, Zagulski T, Kubler A. Lactoferrin lowers serum interleukin 6 and tumor necrosis factor a levels in mice subjected to surgery. Arch Immunol Ther Exp (Warsz). 1998;46:97-104.

9. Cornish J, Callon KE, Naot D, Palmano KP, Banovic T, Bava U, Watson M, Lin JM, Tong PC, Chen Q, Chan VA, Reid HE, Fazzalari N, Baker HM, Baker EN, Haggarty NW, Grey AB, Reid IR. Lactoferrin Is a Potent Regulator of Bone Cell Activity and Increases Bone Formation in Vivo. Endocrinology. 2004; 145(9):4366-74.

10. Montesi M, Panseri S, lafisco M, Adamiano A, Tampieri A. Coupling Hydroxyapatite Nanocrystals with Lactoferrin as a Promising Strategy to Fine Regulate Bone Homeostasis. PLoS One. 2015;10(7):e0132633.

11. Pelletier JP, Lascau-Coman V, Jovanovic D, Fernandes JC, Manning P, Connor JR, Currie MG, Martel-Pelletier J. Selective inhibition of inducible nitric oxide synthase in experimental osteoarthritis is associated with reduction in tissue levels of catabolic factors. J Rheumatol. 1999;26(9): 2002-14.

12. Cornish J, Palmano K, Callon KE, Watson M, Lin JM, Valenti P, Naot D, Grey $A B$, Reid IR. Lactoferrin and bone; structure-activity relationships. Biochem Cell Biol. 2006;84:297-302.

13. Moher D, Liberati A, Tetzlaff J, Altman DG, PRISMA Group. Preferred reporting items for systematic reviews and meta-analyses: the PRISMA statement. PLoS Med. 2009:6(7):e1000097.

14. Yoshimaki T, Sato S, Kigami R, Tsuchiya N, Oka S, Arai Y, Ito K. Bone Regeneration by Lactoferrin in Non-Critical-Sized Rat Calvarial Bone Defects. J Med Biological Eng. 2014;34:256-60.

15. Yoshimaki T, Sato S, Tsunori K, Shino H, Iguchi S, Arai Y, Ito K, Ogiso B. Bone regeneration with systemic administration of lactoferrin in non-critical-sized rat calvarial bone defects. J Oral Sci. 2013;55(4):343-8.

16. Görmez U, Kürkcü M, E Benlidayi M, Ulubayram K, Sertdemir Y, Dağlioğlu K. Effects of bovine lactoferrin in surgically created bone defects on bone regeneration around implants. J Oral Sci. 2015;57:7-15.

17. Paknejad M, Rokn AR, Yaraghi AA, Elhami F, Kharazifard MJ, Moslemi N. Histologic and histomorphometric evaluation of the effect of lactoferrin combined with anorganic bovine bone on healing of experimentally induced bony defects on rabbit calvaria. Dent Res J (Isfahan). 2012;9:75-80.

18. Gao R, Watson M, Callon KE, Tuari D, Dray M, Naot D, Amirapu S, Munro JT, Cornish J, Musson DS. Local application of lactoferrin promotes bone regeneration in a rat critical-sized calvarial defect model as demonstrated by micro-CT and histological analysis. J Tissue Eng Regen Med. 2018;12(1): 620-6.

19. Jadad AR, Moore RA, Carroll D, Jenkinson C, Reynolds DJ, Gavaghan DJ, McQuay HJ. Assessing the quality of reports of randomized clinical trials: is blinding necessary? Control Clin Trials. 1996;17:1-12.

20. Wells GA, Shea B, O'Connell D, Peterson J, Welch V, Losos M, Tugwell P. The Newcastle-Ottawa Scale (NOS) for assessing the quality of case-control studies in meta-analyses. Eur J Epidemiol. 2015;25:603-5.

21. Higgins JPT, Thompson SG. Quantifying heterogeneity in a meta-analysis. Stat Med. 2002;21(11):1539-58.

22. Eriksson RA, Albrektsson T. The effect of heat on bone regeneration: an experimental study in the rabbit using the bone growth chamber. J Oral Maxillofac Surg. 1984;42(11):705-11.

23. Cohen J. Statistical power analysis for the behavioral sciences: Lawrence Erlbaum; 1988.

24. Hedges LV, Olkin I. Statistical methods for meta-analysis. Academic Press Orlando; 1985

25. Studer R, Jaffurs D, Stefanovic-Racic M, Robbins PD, Evans CH. Nitric oxide in osteoarthritis. Osteoarthritis Cartilage. 1999;7(4):377-9.

26. Li W, Zhu S, Hu J. Bone Regeneration Is Promoted by Orally Administered Bovine Lactoferrin in a Rabbit Tibial Distraction Osteogenesis Model. Clin Orthop Relat Res. 2015:473(7):2383-93.
27. Vorland LH, Ulvatne H, Andersen J, Haukland HH, Rekdal O, Svendsen JO, Gutteberg TJ. Lactoferricin of Bovine Origin is More Active than Lactoferricins of Human, Murine and Caprine Origin. Scand J Infect Dis. 1998;30(5):513-7.

28. Wheeler SL, Holmes RE, Calhoun CJ. Six-year clinicaland histologic study of sinus-lift grafts. Int J Oral Maxillofac Implants. 1996;11:26-34.

29. Tadjoedin ES, de Lange GL, Bronckers AL, Lyaruu DM, Burger EH. Deproteinized cancellous bovine bone (Bio-Oss) as bone substitute for sinus floor elevation. A retrospective, histomorphometrical study of five cases. J Clin Periodontol. 2003;30:261-70.

30. Schlegel AK, Donath K. BIO-OSS-a resorbable bone substitute? Journal Long Term Effects Medical Implants. 1998:8:201-9.

31. Chang PC, Seol YJ, Cirelli JA, et al. PDGF-B gene therapy accelerates bone engineering and oral implant osseointegration. Gene Ther. 2010;17(1):95104.

32. Barboza EP, Caula AL, Caula FO, de Souza RO, Geolas NL, Sorensen RG, Li XJ, Wikesjo UM. Effect of recombinant human bone morphogenetic protein-2 in an absorbable collagen sponge with space-providing biomaterials on the augmentation of chronic alveolar ridge defects. J Periodontol. 2004;75:702-8.

33. Yao X, Bunt C, Cornish J, Quek S-Y, Wen J. Oral Delivery of Bovine Lactoferrin Using Pectin- and Chitosan-Modified Liposomes and Solid Lipid Particles: Improvement of Stability of Lactoferrin. Chem Biol Drug Des. 2015; 86:466-75.

\section{Publisher's Note}

Springer Nature remains neutral with regard to jurisdictional claims in published maps and institutional affiliations.

\section{Ready to submit your research? Choose BMC and benefit from:}

- fast, convenient online submission

- thorough peer review by experienced researchers in your field

- rapid publication on acceptance

- support for research data, including large and complex data types

- gold Open Access which fosters wider collaboration and increased citations

- maximum visibility for your research: over $100 \mathrm{M}$ website views per year

At BMC, research is always in progress.

Learn more biomedcentral.com/submissions 